\title{
Efficacy of quinine against ichthyophthiriasis in common carp Cyprinus carpio
}

\author{
Ilka V. Schumacher ${ }^{1}$, Helmut Wedekind ${ }^{1}$, Mansour El-Matbouli ${ }^{2,3, *}$ \\ ${ }^{1}$ Bavarian State Research Centre for Agriculture, Institute for Fisheries, 82319 Starnberg, Germany \\ ${ }^{2}$ Fish Medicine and Livestock Management, Department for Farm Animals and Veterinary Public Health, \\ University of Veterinary Medicine, 1210 Vienna, Austria \\ ${ }^{3}$ Department of Zoology and Parasitology, College of Science, King Saud University, Riyadh, Saudi Arabia
}

\begin{abstract}
Ichthyophthiriasis, caused by Ichthyophthirius multifiliis, is an economically important worldwide parasitic disease that infects all freshwater fish. Since the banning of malachite green for use in food fish, there has been a great need for alternative therapeutants. The goal of this study was to investigate the efficacy of quinine against $I$. multifiliis. Parasite developmental stages from our laboratory-established life cycle in rainbow trout Oncorhynchus mykiss were exposed to quinine in vitro, and a dual fluorescent staining technique was used to allow a clear distinction between viable and damaged parasites. Furthermore, the effect of quinine was assessed in vivo by oral administration and intraperitoneal injections in common carp Cyprinus carpio. The results of the in vitro experiments proved quinine to be effective against the parasite. Quinine injected at a dosage of $60 \mathrm{mg} \mathrm{kg}^{-1}$ body weight resulted in a significantly lower number of trophonts. In contrast, in-feed trials did not show a significant reduction of trophonts after treatment commencing $1 \mathrm{~d}$ after infection with concentrations of up to $20 \mathrm{~g}$ quinine $\mathrm{kg}^{-1}$ feed for $3 \mathrm{~d}$. After a 14-d treatment at concentrations of up to $10 \mathrm{~g}$ quinine $\mathrm{kg}^{-1}$ feed prior to theront exposure, there was also no significant difference in parasite numbers between treated and control groups. The results of oral versus parenteral application of quinine indicate that the substance is not completely absorbed from the intestinal tract of common carp. However, medicated feed containing higher concentrations of quinine was less readily accepted by the fish, presumably due to the bitter taste.
\end{abstract}

KEY WORDS: Quinine · Therapy · Ichthyophthiriasis · Ichthyophthirius multifiliis · Medicated feed · Cyprinus carpio

Resale or republication not permitted without written consent of the publisher

\section{INTRODUCTION}

Ichthyophthiriasis is a prevalent parasitic disease of freshwater fish, commonly referred to as white spot disease due to the appearance of the macroscopically visible parasites as white spots on the epidermis of infected fish. This disease is caused by Ichthyophthirius multifiliis, a ciliate protozoan, which was first described by Fouquet in 1876 and has a nearly worldwide occurrence. Heavy infections cause high mortality rates, especially under fish farming conditions (Valtonen \& Keränen 1981, Wahli et al. 1993, Buchmann et al. 2001, Jørgensen et al. 2009). The life cycle of the parasite comprises several morphologically distinct stages. The free-swimming infective theront stage penetrates skin and gills of the fish. It develops into the feeding trophont, which matures within the epidermis and actively exits the host as a tomont to encyst on a suitable environmental substrate. Inside the cyst the parasite undergoes numerous divisions to produce the next generation of theronts. The life cycle of $I$. multifiliis is temperature dependent; with increasing water temperatures, development proceeds faster and more divisions take place so that the number of theronts produced is higher (Wahli-Moser 1985). The complex life cycle of the parasite makes the treatment of ichthyophthiriasis difficult as not all parasite stages can be eliminated simultaneously. 
Malachite green is a highly effective agent against Ichthyophthirius multifiliis and is commonly used for the treatment of white spot disease in ornamental fish. However, the application of this substance to food fish has been banned due to its potential mutagenic and teratogenic properties for the consumer (Meyer \& Jorgenson 1983, Alderman 1985, Dickerson 2006, Heinecke \& Buchmann 2009). In most countries, only a few substances are permitted, which are not sufficient to control the disease. Therefore, an efficacious therapeutant is needed that is not potentially hazardous to human health as a residue in muscle tissue. Several studies have evaluated alternatives to malachite green for treatment of the disease (Wahli et al. 1993, Straus \& Griffin 2001, 2002, Ekanem et al. 2004, Heinecke \& Buchmann 2009, Meinelt et al. 2009, Straus \& Meinelt 2009), and the compounds that proved effective against free-swimming stages of the parasite could therefore be suitable as bath treatments. However, treatment of ichthyophthiriasis via bath application is difficult because the therapeutant eliminates neither the trophonts located in the epidermis of the fish nor the encysted tomonts, both of which are less susceptible to chemical treatment than the theronts (Meinelt et al. 2009). Therefore, a medicated feed would be beneficial for treating this disease because it would directly affect the stages on the host, be easier to administrate in aquaculture situations and cause less environmental contamination (Luzardo-Álvarez et al. 2003, Shinn et al. 2003). To date, various substances have been tested for their suitability as in-feed treatments. Lower intensities of infection were achieved with diethylcarbamazine, metronidazole, nitridazole, and secnidazole (Tojo Rodriguez \& Santamarina Fernandez 2001), but, as the authors point out, these compounds could not completely prevent the development of trophonts of I. multifiliis. A reduction in the degree of the infection could also be achieved with triclabendazole in an inclusion complex with $\beta$-cyclodextrin (LuzardoÁlvarez et al. 2003). In the study of Shinn et al. (2003) the oral application of amprolium hydrochloride and clopidol led to a significant reduction of trophont numbers.

Quinine has been used for a long time in the treatment of human malaria. It is a natural white crystalline alkaloid with antipyretic, antimalarial, analgesic and anti-inflammatory properties. Several studies have been performed to evaluate the efficacy of quinine against fish parasites, and an effect was shown for Henneguya sp. (Dohle et al. 2002) and Loma salmonae (Speare et al. 1998). Schäperclaus (1954) described the use of quinine as a bath treatment against ichthyophthiriasis, and Schmahl et al. (1996) showed the efficacy of dietary quinine against this disease in ornamental fish. Due to the lack of therapeutants for ichthyoph- thiriasis in aquaculture, the present study was aimed at testing the efficacy of quinine against Ichthyophthirius multifiliis in vitro and in vivo, especially with respect to its possible use on common carp, a popular species of food fish.

\section{MATERIALS AND METHODS}

Fish and parasites. All in vivo experiments were carried out with specific pathogen-free common carp Cyprinus carpio aged between 6 and 11 mo with body weights of 4 to $15 \mathrm{~g}$ and body lengths of 4 to $9 \mathrm{~cm}$. Fish of equal weight were selected for each experimental trial. The carp for the in-feed experiments were obtained from the Department for Animal Sciences, University of Wageningen, Netherlands, and those for the injection experiments from the Bavarian State Research Centre for Agriculture, Institute for Fisheries, Germany. Prior to the experiments, the carp were held in aerated 2001 aquaria with constantly flowing tap water at temperatures of $18 \pm 1^{\circ} \mathrm{C}$.

Ichthyophthirius multifiliis was maintained in the laboratory using rainbow trout Oncorhynchus mykiss as host fish. These were raised in our facilities, were aged between $10 \mathrm{mo}$ and $3 \mathrm{yr}$, and had body lengths of 8 to $17 \mathrm{~cm}$ and body weights of 15 to $150 \mathrm{~g}$. They were kept in constantly flowing tap water at temperatures of $16 \pm 3^{\circ} \mathrm{C}$.

The laboratory life cycle of Ichthyophthirius multifiliis was initiated by cohabitation of naïve rainbow trout with naturally infected grayling Thymallus thymallus obtained from a local fish farm. Infected rainbow trout were kept in 2501 aquaria containing 20 to 30 fish each. Dead or moribund fish and those which had developed immunity against the parasite were removed and replaced by naïve rainbow trout. To monitor the life cycle, parasite stages were counted in skin scrapings of several fish. If necessary, the infection intensity was regulated by changing the parameters that influence the parasite development (e.g. the velocity of the current, the density of fish in the aquaria, water temperature).

In vitro trials. In vitro experiments were carried out to evaluate the effect of quinine dihydrochloride (Carl Roth) on the different developmental stages of Ichthyophthirius multifiliis: theronts (the free-swimming infective stage), trophonts (the adult parasite freshly scraped off the fish), and tomonts (the encysted reproductive stage).

A dual fluorescent staining technique using propidium iodide (PI) and fluorescein diacetate (FDA) allowed the clear distinction between viable and damaged parasites by fluorescent microscopy. This technique has already been used successfully in studies on 
other fish parasites (Markiw 1992, Yokoyama et al. 1997, Kallert et al. 2007). PI intercalates with DNA of cells and can only permeate through damaged cell membranes. The non-fluorescent FDA is converted into the green compound fluorescein by viable cells. Therefore, intact parasite stages emit a green fluorescence, whereas dead or damaged cells fluoresce red under a fluorescence microscope.

Trophonts of Ichthyophthirius multifiliis were harvested from visibly infected rainbow trout kept for maintaining the parasite life cycle. The fish were euthanized with an overdose of MS-222 (150 mg l-1; Phar$\mathrm{maQ}$ ) and their mucus layer was carefully scraped into Petri dishes containing $10 \mathrm{ml}$ of water $\left(16^{\circ} \mathrm{C}\right)$. After the trophonts had actively left the mucus, they could be collected with a pipette and either put into plastic test tubes for the experiment or used to produce theronts or tomonts. For theront production, the trophonts were put into Petri dishes (approximately 50 trophonts per dish) with $10 \mathrm{ml}$ of tap water and incubated at $22^{\circ} \mathrm{C}$ for $20 \mathrm{~h}$, after which time the theronts had hatched. To determine the number of theronts in the Petri dishes, 10 samples of $20 \mu \mathrm{l}$ were put on slides, fixed with $5 \mu \mathrm{l}$ Roti-Histofix ${ }^{\circledR}$ (Carl Roth) and counted under a microscope. The mean of the sample counts served to assess the total number of theronts produced. To obtain tomonts, the Petri dishes with trophonts were incubated for only $18 \mathrm{~h}$ at $14^{\circ} \mathrm{C}$ so that the development of theronts had not been completed. A stereo microscope was used to transfer the cysts into the plastic tubes for the experiment.

The experimental trials were carried out in $200 \mu \mathrm{l}$ of water in four $2 \mathrm{ml}$ plastic tubes containing approximately the same number of either trophonts, theronts or tomonts at a time. The tested concentrations of quinine (dissolved in tap water) were 0 (control), $1,0.1$ and $0.01 \mathrm{~g} \mathrm{l}^{-1}$. The $\mathrm{pH}$ of each quinine solution was measured with a $\mathrm{pH}$ meter at a temperature of $21^{\circ} \mathrm{C}$ to exclude the possibility that toxic effects on the parasites were caused by a change of $\mathrm{pH}$. After adding the quinine solutions, the test tubes were incubated for $30 \mathrm{~min}$ in darkness. Then $2 \mu \mathrm{l}$ of PI work solution (0.5 mg PI ml ${ }^{-1}$ phosphate-buffered saline) and $1 \mu \mathrm{l}$ of FDA work solution (5 mg FDA ml-1 acetone) were added, and the tubes were incubated for another $30 \mathrm{~min}$ in darkness. Samples of each test tube were prepared for microscopy, and the ratio of red to green stages was assessed using a fluorescence microscope (Olympus BH-2 RFCA; Olympus Optical). The experiment was replicated 7 times with trophonts and theronts and only 3 times with tomonts, as adequate numbers of the latter stage were more difficult to collect without damaging the fragile cyst wall.

In vivo experiments. Infection procedure: To ascertain adequate numbers of parasite stages on the fish, the carp were infected with Ichthyophthirius multifiliis by placing in vitro-produced theronts into the water. The theronts were raised from cysts as described for the in vitro trials. All carp were kept in a 401 aquarium with a current of tap water at $17 \pm 2{ }^{\circ} \mathrm{C}$ for $2 \mathrm{~d}$. On each day approximately 1000 theronts per fish were added after reducing the water volume to $20 \mathrm{l}$. Current and aeration were turned off for $3 \mathrm{~h}$ after the addition to allow optimal contact between parasites and hosts.

Production of medicated feed: A pelleted carp feed (40\% fish meal, $20 \%$ soy protein-isolate, $15 \%$ cornstarch, $15 \%$ wheat, $6 \%$ fish oil, $4 \%$ vitamin/mineral mix) containing quinine in the desired concentrations $\left(0,5,10\right.$, and $\left.20 \mathrm{~g} \mathrm{~kg}^{-1}\right)$ was produced at the Department for Animal Nutrition of the Technical University of Munich and the Department for Animal Nutrition of the Faculty for Veterinary Medicine of the LudwigMaximilians-University of Munich. To improve the palatability, several substances were tested in preexperiments: sweet substances (e.g. sugar, mannitol), fats (cod-liver oil, fish oil), amino acids (juice of pressed chironomid larvae), commercial carp flavors (XL Liquid Worm®, XL Liquid Pineapple®: Dynamite Baits; DD Bait Mussel Meat Liquid Dip®: Svendsen Sport Deutschland). The feed that proved to be accepted best by the fish were pellets top-coated with fish oil and carp flavor (XL Liquid Pineapple®, Dynamite Baits)

In-feed trials. Orally administered quinine was tested on carp infected with Ichthyophthirius multifiliis in the early trophont stage. After the infection period, the carp were divided into the different treatment groups, which were each held in an aerated static 101 aquarium at temperatures of $18 \pm 1^{\circ} \mathrm{C}$. Water changes $(25 \%)$ were carried out daily. Treatment with medicated feed was started $1 \mathrm{~d}$ after the infection. Four treatment groups, each consisting of 5 carp, received feed containing quinine at 0 (control feed), 5, 10, or $20 \mathrm{~g}$ quinine per $\mathrm{kg}$ of feed. The fish were fed a $1 \%$ body weight ration divided into 2 feedings a day for $3 \mathrm{~d}$. The fish were observed from a distance to evaluate the duration of feed uptake. To assess the level of infection at the end of the experiment, all fish were euthanized using an overdose of MS-222. The total number of parasites on the body surface of each fish was counted at $40 \times$ magnification using an inverse microscope (Zeiss Axiovert 25; Carl Zeiss). The experiment was replicated 4 times.

A second experiment was performed to test whether quinine could be used to prevent the outbreak of ichthyophthiriasis. Fish received medicated feed for $14 \mathrm{~d}$ prior to exposure to the parasite. Each group consisted of 5 carp and was held in an aerated static 101 aquarium at temperatures of $18 \pm 1^{\circ} \mathrm{C}$. Water changes $(25 \%)$ were carried out daily. The quinine concentra- 
tions fed were 0 (control), 5, and $10 \mathrm{~g} \mathrm{~kg}^{-1}$. As preliminary experiments had shown that the acceptance of the feed with $20 \mathrm{~g}$ quinine $\mathrm{kg}^{-1}$ decreased after $3 \mathrm{~d}$ of treatment, a maximum concentration of $10 \mathrm{~g} \mathrm{~kg}^{-1}$ was used in this experiment. The fish were observed from a distance to evaluate the duration of feed uptake. After the last day of treatment, the fish were infected as described above. Subsequent to the infection process, all carp were transferred to a $40 \mathrm{l}$ aquarium $\left(18 \pm 1^{\circ} \mathrm{C}\right)$ for $2 \mathrm{~d}$ to allow the theronts to mature to the trophont stage, which facilitated the counting of the parasites. At the end of the experiment the differences in the parasite load between the control and the quinine-treated groups were assessed as described in 'Infection procedure'. The experiment was replicated 6 times.

Injection trials. After infection with Ichthyophthirius multifiliis as described in 'Infection procedure', 12 common carp were separated into a control group and a treatment group, the latter receiving quinine injections at a dosage of $60 \mathrm{mg} \mathrm{kg}^{-1}$ body weight. After sedation with MS-222 each fish was injected intraperitoneally with $30 \mu \mathrm{l}$ of the injection solutions once a day over a period of $3 \mathrm{~d}$. The solution for the control group consisted of $2500 \mu \mathrm{l}$ water and $500 \mu \mathrm{l}$ dimethylsulfoxide. For the treatment group, the necessary amount of quinine was added based on the average weight of the fish. The experiment was replicated 4 times. The number of parasites was assessed as described above, with the addition that the parasites were categorized according to size. Parasites $\leq 120 \mu \mathrm{m}$ were considered 'small' and those $>120 \mu \mathrm{m}$ 'big'.

Statistics. For the in vitro trials the percent values of viable (green fluorescent) stages were arc-sine transformed and compared between quinine-treated samples and the control. A Kruskal-Wallis test was used, followed by Dunn's multiple test of chosen means. Dif- ferences were considered significant at $\mathrm{p}<0.05$. For the in vivo experiments the ratio of parasite numbers between control and treated groups was used. If there was a difference between treatment and control group, the quotient of the parasite number of the treated group divided by the parasite number of the control group would be significantly smaller than 1 . This was tested using a 1-sample $t$-test. A difference was considered to be significant at $\mathrm{p}<0.05$.

\section{RESULTS}

\section{In vitro experiments}

Most stages of Ichthyophthirius multifiliis were either stained clearly red or green by the PI/FDA dual staining technique (Figs. 1 \& 2). In addition to red and green fluorescent stages, there were also mixed stages that had a green fluorescent cell membrane and were red fluorescent on the inside (Fig. 1). As the cell membrane of these stages was already damaged before or during staining, they were treated as 'dead'. The $\mathrm{pH}$ of the applied quinine solutions was 7.5 for the control, 0.01 , and $0.1 \mathrm{~g} \mathrm{l}^{-1}$ treatments and 7.42 for the $1 \mathrm{~g} \mathrm{l}^{-1}$ treatment.

Trophonts. For trophonts, the efficacy of quinine showed a concentration-dependent pattern. In the control, the proportion of green fluorescent (viable) trophonts was $85.35 \%$. At a quinine concentration of $1 \mathrm{~g} \mathrm{l}^{-1}$, the proportion of viable trophonts was $1.58 \%$ and at $0.1 \mathrm{~g} \mathrm{l}^{-1}$ it was $17.71 \%$, both of which were significantly different to the control $(p<0.05)$. At the lowest concentration tested $\left(0.01 \mathrm{~g} \mathrm{l}^{-1}\right)$, the viable parasites predominated $(88.00 \%)$, which did not differ significantly from the control (Fig. 3).
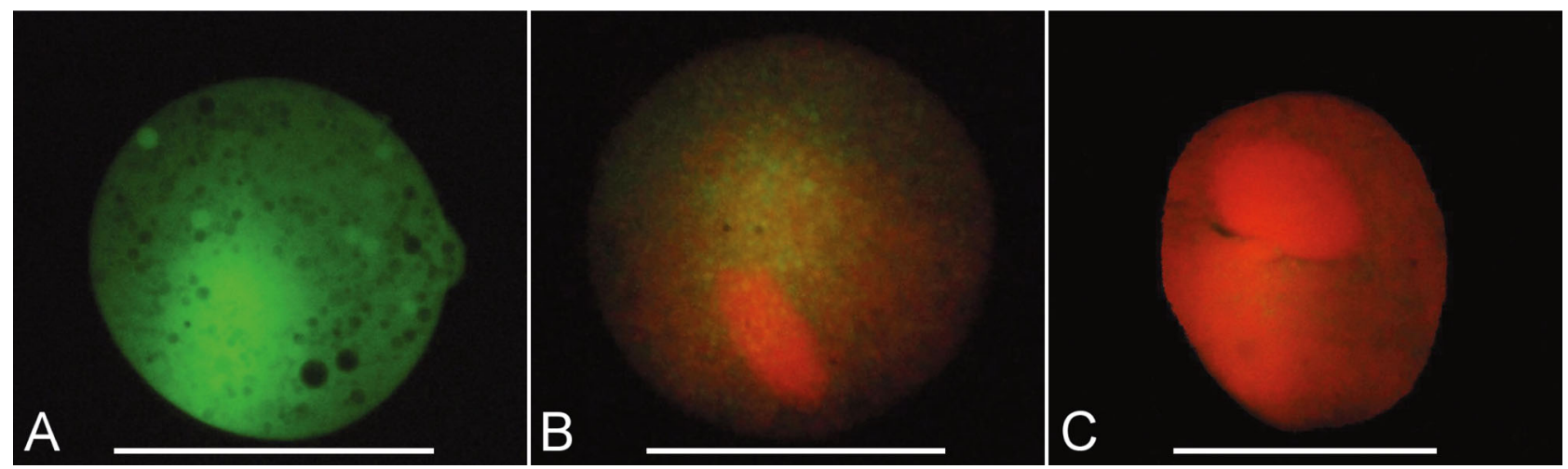

Fig. 1. Ichthyophthirius multifiliis. Trophonts after staining with the fluorescent dyes propidium iodide (PI) and fluorescein diacetate (FDA). (A) Trophont of control. Green fluorescence indicates viability of the parasite. (B) Trophont emitting both red and green fluorescence after exposure to quinine at a concentration of $0.1 \mathrm{~g} \mathrm{l}^{-1}$ for $60 \mathrm{~min}$, a response which indicates that the parasite was in the process of dying when stains were added. (C) Trophont after exposure to quinine at a concentration of $1 \mathrm{~g} \mathrm{l}^{-1}$ for $60 \mathrm{~min}$. Red fluorescence indicates impairment of cell membrane. Scale bars $=500 \mu \mathrm{m}$ 

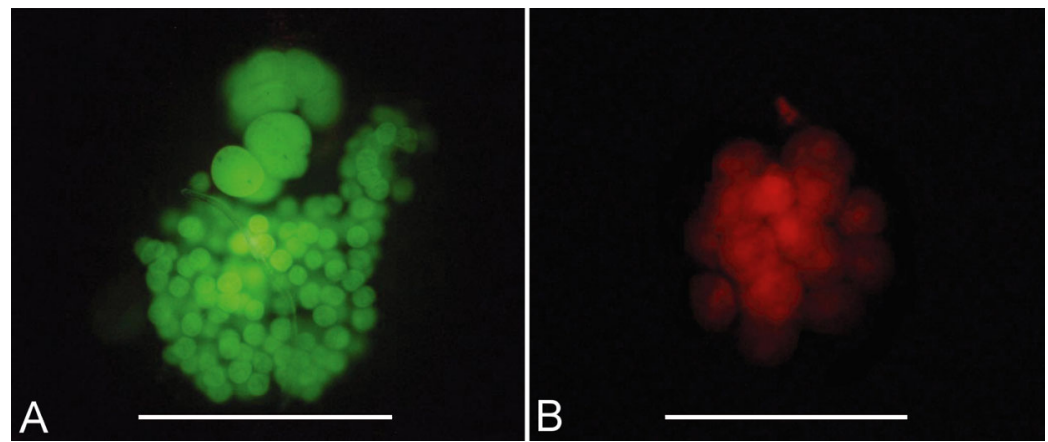

Fig. 2. Ichthyophthirius multifiliis. Tomonts after staining with the fluorescent dyes fluorescein diacetate (FDA) and propidium iodide (PI). In both images, the division products (tomites) inside the tomonts are clearly visible. The cyst wall is not visible with this staining technique. (A) Tomont of control. Green fluorescence indicates viability of the parasite stage. (B) Tomont after exposure to quinine at a concentration of $1 \mathrm{~g} \mathrm{l}^{-1}$ for $60 \mathrm{~min}$. Red fluorescence indicates impairment of cell membrane. Scale bars $=300 \mu \mathrm{m}$

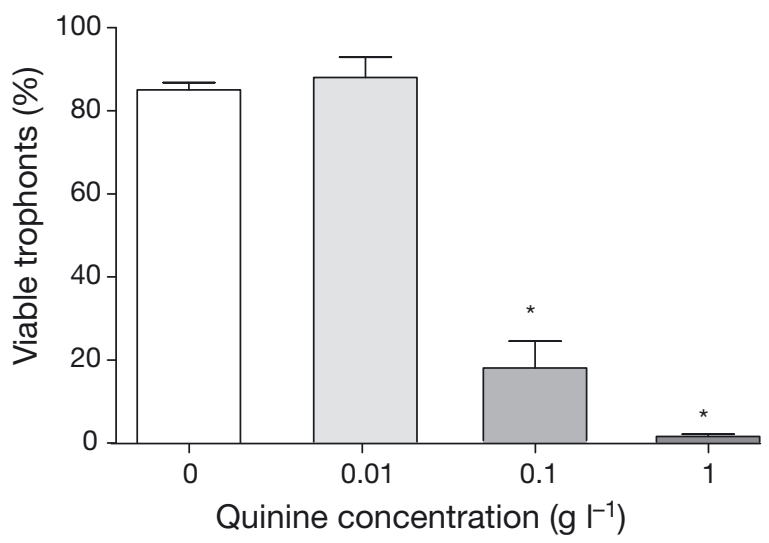

Fig. 3. Ichthyophthirius multifiliis. In vitro efficacy of quinine on trophonts after staining with the fluorescent dyes fluorescein diacetate (FDA) and propidium iodide (PI). Mean (SE) percentage of viable trophonts for each quinine concentration tested are shown. The experiment was replicated 7 times. ${ }^{*} \mathrm{p}<0.05$

Tomonts. Inside the tomonts, the division products (tomites) were visible and emitted either green, red, or mixed fluorescence. In the control, the number of green fluorescent (viable) tomonts predominated $(96.67 \%)$. At the 2 highest concentrations of quinine tested ( 1 and $0.1 \mathrm{~g} \mathrm{l}^{-1}$ ), $100 \%$ of the tomonts were red fluorescent (dead). At the lowest concentration $(0.01 \mathrm{~g}$ $\left.\mathrm{l}^{-1}\right), 86.87 \%$ of the tomonts were viable. Statistical differences could not be assessed due to a small number of replicates $(n=3)$.

Theronts. Theronts were found to be highly sensitive to the treatment. In the control, $86.40 \%$ of theronts were viable, whereas at concentrations of 0.01 and $0.1 \mathrm{~g} \mathrm{l}^{-1}, 99$ and $100 \%$ of theronts, respectively, were red fluorescent (dead) (Fig 4). The number of viable theronts was therefore significantly lower than the control at all quinine concentrations $(p<0.05)$.

\section{In vivo experiments}

In-feed trials. In the trials testing the therapeutic efficacy of quinine, the majority of the feed pellets were consumed by the carp of all treatment groups over the $3 \mathrm{~d}$ of treatment. There was no significant difference in the number of trophonts between the quinine-treated groups and the control group (Fig. 5).

In the trials testing the prophylactic efficacy of quinine, the control group and the group receiving $5 \mathrm{~g} \mathrm{~kg}^{-1}$ feed completely consumed their rations over the whole period of treatment. In the group treated with $10 \mathrm{~g} \mathrm{~kg}^{-1}$ feed, the uptake of the medicated feed diminished after 8 to $9 \mathrm{~d}$. The carp became more hesitant, parts of the ration were left, and sometimes the pellets were taken in at first and then spat out. However, the majority of the pellets were always eaten. No significant difference in the number of trophonts could be found between the groups receiving medicated feed and the control group (Fig. 6).

Injection experiments. In the control group, no fish showed adverse symptoms to the 3 injections in any of the 4 replicates. In 2 replicates 2 carp died in the quinine-treated group. Dissections of the fish revealed no mechanical trauma caused by the injections and because no fish of the control group died, the deaths

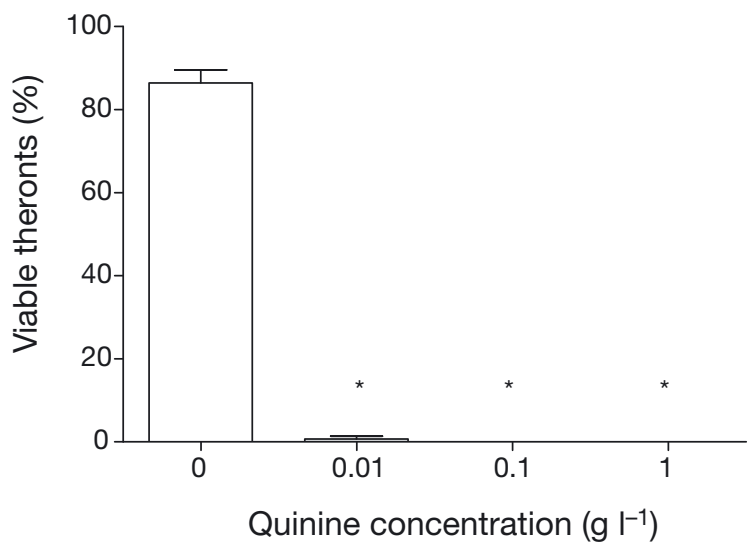

Fig. 4. Ichthyophthirius multifiliis. In vitro efficacy of quinine on theronts after staining with the fluorescent dyes fluorescein diacetate (FDA) and propidium iodide (PI). Mean percentage (SE) of viable parasites for each quinine concentration tested is shown. The experiment was replicated 7 times. ${ }^{*} \mathrm{p}<0.05$ 


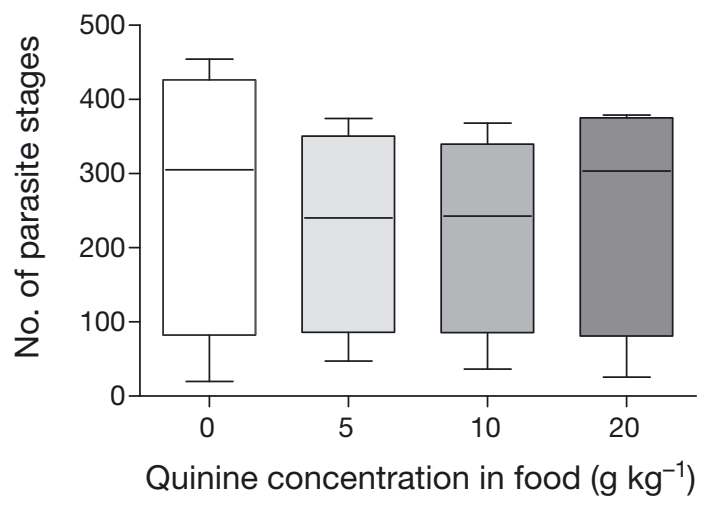

Fig. 5. Cyprinus carpio and Ichthyophthirius multifiliis. Infeed trials for testing the therapeutic efficacy of quinine on carp infested with parasite trophonts after treatment with medicated feed over $3 \mathrm{~d}$. Boxplot limits show median (line), 25th -75 th percentile (box) and data range (whiskers). There was no significant difference between control and treatment groups ( $\mathrm{p}>0.05, \mathrm{n}=5$ fish per group, 4 replications)

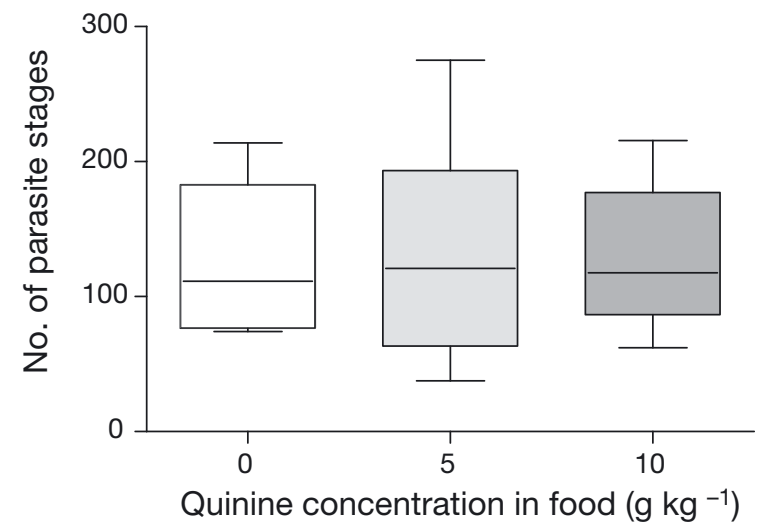

Fig. 6. Cyprinus carpio and Ichthyophthirius multifiliis. Infeed trials for testing the prophylactic efficacy of quinine. Carp were treated with medicated feed over $14 \mathrm{~d}$ prior to infection with the parasite. Boxplot limits as in Fig. 5. There was no significant difference between control and treated groups ( $\mathrm{p}>0.05, \mathrm{n}=6$ fish per group, 6 replications)

were likely to be caused by toxic properties of the quinine. The results showed a significant difference in the total number of trophonts between the control and the group injected with $60 \mathrm{mg}$ quinine $\mathrm{kg}^{-1}$ body weight $(p<0.05)$ (Fig. 7). In the quinine-treated fish there was a reduction in the number of parasites, and, additionally, those collected from these fish were smaller than those from the control group (Fig. 8).

\section{DISCUSSION}

The present study provides important information about the in vitro and in vivo efficacy of quinine against ichthyophthiriasis. Maintaining a laboratory

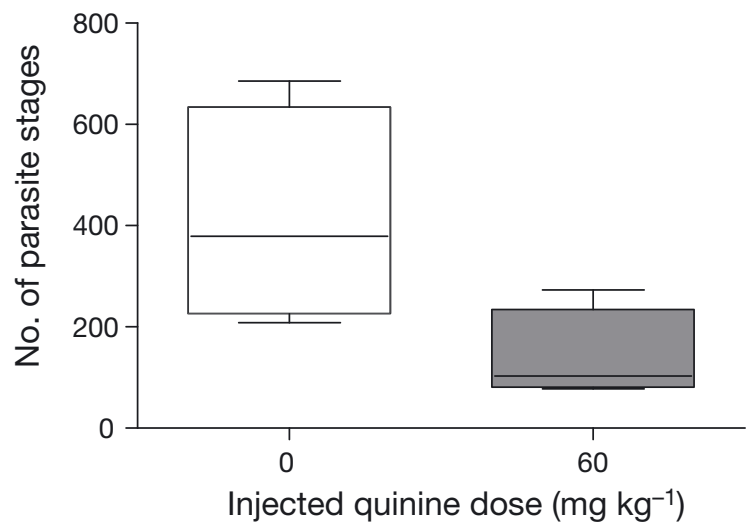

Fig. 7. Cyprinus carpio and Ichthyophthirius multifiliis. Injection trials for testing the therapeutic efficacy of quinine after carp were treated with intraperitoneal injections of $60 \mathrm{mg}$ quinine $\mathrm{kg}^{-1}$ body weight daily for $3 \mathrm{~d}$. Boxplot limits as in Fig. 5. The difference in parasite numbers between control and treated group was statistically significant $(\mathrm{p}<0.05, \mathrm{n}=6$ fish per group, 4 replications)

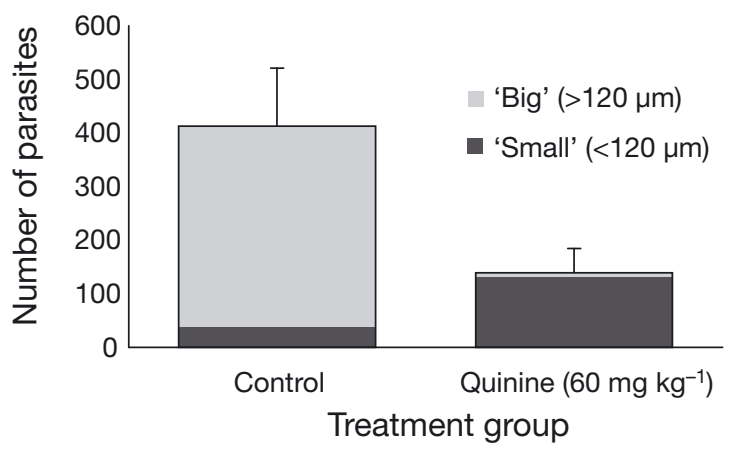

Fig. 8. Cyprinus carpio and Ichthyophthirius multifiliis. Therapeutic efficacy of quinine after carp were treated with intraperitoneal injections of $60 \mathrm{mg}$ quinine $\mathrm{kg}^{-1}$ body weight daily for $3 \mathrm{~d}$. Mean $(+\mathrm{SE})$ number of parasites detected in control and treated groups $(\mathrm{n}=6$ fish) of all replicates $(\mathrm{n}=4)$ is shown. The difference in parasite numbers between control and treated group was statistically significant $(p<0.05)$. Also visible is the difference in trophont sizes between the control and treated groups

life-cycle system of Ichthyophthirius multifiliis was necessary for the experiments, because the parasite is not culturable in vitro (Noe \& Dickerson 1995, Dickerson 2006). Rainbow trout were used to maintain the parasite life cycle, but the main experiments of the present study were carried out with common carp. This change in host species, however, was not expected to affect the success of the experimental trials as I. multifiliis has a low degree of host specificity (Matthews 2005) and can easily be transmitted from salmonids to cyprinids (Wahli-Moser 1985).

The results of the in vitro experiments show that quinine is effective against all stages of Ichthyophthirius multifiliis. As expected, in the control group the major- 
ity of all stages were viable, as indicated by green fluorescence. A few red fluorescent stages were also present in the control, probably due to the inevitable damage of a few stages during the transfer of parasites into the test tubes and the mixing in the tubes. At concentrations of 1 and $0.1 \mathrm{~g}$ quinine $\mathrm{l}^{-1}$ there was a noticeable effect on all stages after an incubation time of $60 \mathrm{~min}$, whereas at a concentration of $0.01 \mathrm{~g} \mathrm{l}^{-1}$, quinine was ineffective against tomonts and trophonts. These results are in accordance to those of Schäperclaus (1954), who showed quinine was effective against $I$. multifiliis at a concentration of $1 \mathrm{~g} \mathrm{l}^{-1}$ within $20 \mathrm{~min}$, at $0.1 \mathrm{~g} \mathrm{l}^{-1}$ within $45 \mathrm{~min}$ and at $0.01 \mathrm{~g} \mathrm{l}^{-1}$ after $7 \mathrm{~h}$; however, it is unclear which parasite stages were used in that study. In the present study, the effect of quinine was tested for the first time on all stages of the parasite using a fluorescent vital staining technique. Interestingly, the lowest concentration of quinine tested $\left(0.01 \mathrm{~g} \mathrm{l}^{-1}\right)$ was still significantly effective against theronts but not against trophonts and tomonts. Thus, the theronts can be concluded to be more susceptible to quinine than the other 2 stages.

The in-feed experiments of the present study did not demonstrate an efficacy of quinine against ichthyophthiriasis. There was no protection against subsequent exposure to theronts after a $14 \mathrm{~d}$ treatment with concentrations of up to $10 \mathrm{~g}$ quinine $\mathrm{kg}^{-1}$ feed and also no significant reduction of trophont numbers after receiving the medicated feed commencing $1 \mathrm{~d}$ after infection at quinine amounts of up to $20 \mathrm{~g} \mathrm{~kg}^{-1}$. These results are in contradiction to the study of Schmahl et al. (1996), where a significant reduction of parasites in ornamental fish was achieved at a quinine concentration of only $5 \mathrm{~g}$ $\mathrm{kg}^{-1}$. Possibly, the absorption of quinine from the intestinal tract was influenced by the differences in fish species and the disparate composition of the medicated feed used in the 2 studies. Furthermore, the water temperature could have been responsible, as experiments of the present study were conducted at approximately $18^{\circ} \mathrm{C}$, whereas the fish in Schmahl et al.'s (1996) study were kept at $25^{\circ} \mathrm{C}$. Therefore, comparing the efficacy of quinine under the influence of various water temperatures would be worthwhile. Schmahl et al. (1996) treated the fish with the medicated feed for up to $10 \mathrm{~d}$. In the present study, however, the substance was fed for only $3 \mathrm{~d}$. In pre-experiments, a longer period of treatment was also tested, but the results could not be evaluated because the trophonts had already matured and left the fish to encyst so they were consequently undetectable on the fish. Therefore, the duration of treatment was shortened so that the parasite load could be assessed during the first infection cycle, which had the additional advantage that all treatment groups accepted the feed over this period. If quinine had the desired effect, a reduction of parasite numbers should al- ready have been evident after that time, as was the case for Schmahl et al. (1996).

Since quinine did not prove to be successful in the in-feed experiments, the potential for a high concentration of the substance to have an effect was tested. A dose of $60 \mathrm{mg} \mathrm{kg}^{-1}$ body weight significantly reduced the number of parasites. The remaining trophonts were also smaller compared to those found on the control fish, which indicated that quinine delayed the development of the parasites. As the drug was injected over a period of $3 d$, the parasites on the fish of the control group grew normally, whereas the parasites in the treated fish were damaged or killed by the quinine injections so that they did not mature further. These observations are in accordance to those of LuzardoÁlvarez et al. (2003), where the trophonts on the fish treated with an orally administered drug were also smaller than those on the control fish.

Several explanations are possible for quinine's lack of efficacy by oral administration in comparison with injection. The drug was unlikely to have been washed out of the feed considering its homogeneous distribution within the pellets and their immediate consumption by the fish. However, the pellets were frequently observed to be chewed for a long time, which might have led to dispersion of the feed through the gills and a consequent loss of the therapeutic substance. Moreover, quinine was presumably not completely absorbed from the intestinal tract but excreted with food components. In addition, quinine undergoes a presystemic elimination by the liver after oral administration (Schäperclaus 1990). Therefore, the bioavailablity of the drug is higher when injected, so that raising the concentrations of quinine in the feed may be necessary in order for an effect to occur. However, the unpalatability of highly medicated feed, presumably caused by the bitter taste of the substance, made using higher concentrations impossible. This problem also occurred in other studies (Schmahl et al. 1996, Speare et al. 1998). In pre-experiments, several ways were tested to improve the palatability of the medicated diet by coating it with different flavors, and the feed best accepted by the fish was used for the main experiments. However, the bitterness could not be completely masked so that a further increase of the quinine concentrations in the feed was not possible.

The results achieved in this study show that quinine is effective against Ichthyophthirius multifiliis and therefore could be a new option for therapy. Table 1 of the council regulation (EU) No. 37/2010 of the European Union states that 'Cinchonae cortex, standardized extracts and preparations thereof' are permitted for treatment of all food-producing species, whereas quinine as a pure substance is not listed. Thus, the legal aspects of its use in fish for human consumption 
have to be clarified. In this context, limited concentrations of quinine are permitted to be added to beverages for taste improvement. The residue of the drug in fish muscle resulting from the treatment of food fish is unlikely to reach such a level that would endanger the consumer's health.

In summary, the results of the in vitro as well as in vivo experiments with parenteral application demonstrate that quinine is effective against the skininhabiting trophonts of Ichthyophthirius multifiliis. The lack of prophylactic and therapeutic effects of quinine via oral administration indicate that further work will be required to develop a palatable medicated feed with an adequate oral bioavailability to allow the usage of quinine as a suitable therapeutant for ichthyophthiriasis in aquaculture.

Acknowledgements. The authors gratefully acknowledge the Bayerische Staatsministerium für Ernährung, Landwirtschaft und Forsten for financing this work from the fund Fischereiabgabe des Freistaats Bayern. We gratefully appreciate the help of D. Grabner and D. Kallert who substantially contributed to this study with valuable advice and technical support. We thank F. J. Schwarz and the Department for Animal Nutrition of the Technical University of Munich and E. Kienzle and the Department for Animal Nutrition of the Faculty for Veterinary Medicine of the Ludwig-Maximilians-University of Munich for helping with the production of the medicated feed.

\section{LITERATURE CITED}

Alderman DJ (1985) Malachite green: a review. J Fish Dis 8: 289-298

- Buchmann K, Sigh J, Nielsen CV, Dalgaard M (2001) Host responses against the fish parasitizing ciliate Ichthyophthirius multifiliis. Vet Parasitol 100:105-116

Dickerson HW (2006) Ichthyophthirius multifiliis and Cryptocaryon irritans (Phylum Ciliophora). In: Woo PTK (ed) Fish diseases and disorders, 2nd edn, Vol 1: Protozoan and metazoan infections. CAB International, Wallingford, p 116-153

Dohle A, Schmahl G, Raether W, Schmidt H, Ritter G (2002) Effects of orally administered chemotherapeutics (quinine, salinomycin) against Henneguya sp. Thelohán, 1892 (Myxozoa: Myxobolidae), a gill parasite in the tapir fish Gnathonemus petersii Günther, 1862 (Teleostei). Parasitol Res 88:861-867

Ekanem AP, Obiekezie A, Kloas W, Knopf K (2004) Effects of crude extracts of Mucuna pruriens (Fabaceae) and Carica papaya (Caricaceae) against the protozoan fish parasite Ichthyophthirius multifiliis. Parasitol Res 92:361-366

> Heinecke RD, Buchmann K (2009) Control of Ichthyophthirius multifiliis using a combination of water filtration and sodium percarbonate: dose-response studies. Aquaculture 288:32-35

Jørgensen TR, Larsen TB, Buchmann K (2009) Parasite infections in recirculated rainbow trout (Oncorhynchus mykiss) farms. Aquaculture 289:91-94

Kallert DM, Ponader S, Eszterbauer E, El-Matbouli M, Haas W (2007) Myxozoan transmission via actinospores: new insights into mechanisms and adaptations for host invasion. Parasitology 134:1741-1750
Luzardo-Álvarez A, Martinez-Mazagatos J, SantamarinaFernandez MT, Otero-Espinar FJ, Blanco-Mendez J (2003) Oral pharmacological treatments for ichthyophthiriosis of rainbow trout (Oncorhynchus mykiss). Aquaculture 220: $15-25$

Markiw ME (1992) Experimentally induced whirling disease II. Determination of longevity of the infective triactinomyxon stage of Myxobolus cerebralis by vital staining. J Aquat Anim Health 4:44-47

Matthews RA (2005) Ichthyophthirius multifiliis Fouquet and ichthyophthiriosis in freshwater teleosts. Adv Parasitol 59: 159-241

Meinelt T, Matzke S, Stüber A, Pietrock M, Wienke A, Mitchell AJ, Strauss DL (2009) Toxicity of peracetic acid (PAA) to tomonts of Ichthyophthirius multifiliis. Dis Aquat Org 86:51-56

Meyer FP, Jorgenson FA (1983) Teratological and other effects of malachite green on development of rainbow trout and rabbits. Trans Am Fish Soc 112:818-824

> Noe JG, Dickerson HW (1995) Sustained growth of Ichthyophthirius multifiliis at low temperature in the laboratory. J Parasitol 81:1022-1024

Schäperclaus W (1954) Fischkrankheiten, 3rd edn. Akademie Verlag, Berlin

Schäperclaus W (1990) Fischkrankheiten, 5th edn. Akademie Verlag, Berlin

Schmahl G, Schmidt H, Ritter G (1996) The control of ichthyophthiriasis by a medicated food containing quinine: efficacy tests and ultrastructure investigations. Parasitol Res 82:697-705

Shinn AP, Wootten R, Côté I, Sommerville C (2003) Efficacy of selected oral chemotherapeutants against Ichthyophthirius multifiliis (Ciliophora: Ophyroglenidae) infecting rainbow trout Oncorhynchus mykiss. Dis Aquat Org 55: $17-22$

> Speare DJ, Ritter G, Schmidt H (1998) Quinine hydrochloride treatment delays xenoma formation and dissolution in rainbow trout challenged with Loma salmonae. J Comp Pathol 119:459-465

Straus DL, Griffin BR (2001) Prevention of an initial infestation of Ichthyophthirius multifiliis in channel catfish and blue tilapia by potassium permanganate treatment. N Am J Aquaculture 63:11-16

Straus DL, Griffin BR (2002) Efficacy of potassium permanganate in treating ichthyophthiriasis in channel catfish. J Aquat Anim Health 14:145-148

Straus DL, Meinelt T (2009) Acute toxicity of peracetic acid (PAA) formulations to Icthyophthirius multifiliis theronts. Parasitol Res 104:1237-1241

Tojo Rodriguez JL, Santamarina Fernandez MT (2001) Attempts at oral pharmacological treatment of Ichthyophthirius multifiliis in rainbow trout, Oncorhynchus mykiss (Walbaum). J Fish Dis 24:249-252

> Valtonen ET, Keränen A (1981) Ichthyophthiriasis of Atlantic salmon, Salmo salar L., at the Montta Hatchery in northern Finland in 1978-1979. J Fish Dis 4:405-411

Wahli T, Schmitt M, Meier W (1993) Evaluation of alternatives to malachite green oxalate as a therapeutant for ichthyophthiriosis in rainbow trout Oncorhynchus mykiss. J Appl Ichthyol 9:237-249

Wahli-Moser T (1985) Ichthyophthiriasis bei der Forelle (Salmo sp.). PhD thesis, University of Basel

> Yokoyama H, Danjo T, Ogawa K, Wakabayashi H (1997) A vital staining technique with fluorescein diacetate (FDA) and propidium iodide (PI) for the determination of viability of myxosporean and actinosporean spores. J Fish Dis 20:281-286 